\title{
WALTER ZANINI E AS MEDIAÇÕES DA ARTE CONTEMPORÂNEA NO BRASIL EM REDEMOCRATIZAÇÃO
}

\author{
Tálisson Melo de Souza*
}

Resumo: A partir do estudo de processos de mediação institucional e atividades desempenhadas por agentes culturais intermediários, que operaram na emergência e consolidação da "arte contemporânea" como novo paradigma na história da arte no Brasil. Proponho uma análise desse processo, que se deu ao longo dos anos de 1970 e 1980, articulado às condições limitantes e provocantes de um cenário político que experimentava uma transição gradual e tutelada de um regime ditatorial-militar para uma democracia. Foco o estudo sobre a trajetória de um intermediário cultural específico, Walter Zanini, crítico e historiador de arte, museólogo e professor, que dirigiu o Museu de Arte Contemporânea da Universidade de São Paulo entre 1963 e 1978, e foi a primeira pessoa a ocupar o cargo de curador geral para a Bienal Internacional de São Paulo, entre 1980 e 1983 , organizando suas $16^{\mathrm{a}}$ e $17^{\mathrm{a}}$ edições.

Palavras-chave: Sociologia da arte; Arte contemporânea; Curadoria de exposições; Bienal de São Paulo.

\section{INTRODUÇÃO - O CONTEMPORÂNEO NA ARTE COMO CRISE E PARADIGMA}

O historiador de arte e museólogo Jesús Pedro Lorente (2008) nos oferece uma história dos museus de arte contemporânea como uma das instituições de controle social da modernidade, partindo de dois pontos nodais como modelos ou paradigmas que nortearam projetos de emulação e contestação no curso da proliferação de museus de arte ao longo dos séculos XIX, XX e início deste século: nomeadamente, (i) o Musée des Artistes Vivants inaugurado em 1818, reabrindo a galeria do Palácio de Luxemburgo em Paris, com 74 pinturas representativas da arte atual francesa; e (ii) o Museum of Modern Art de Nova York, fundado em 1929 em pleno centro de Manhattan, com o jovem professor de história de arte Alfred Barr Jr. (1902-1981) ocupando o cargo de seu diretor. A partir desses dois casos, Lorente aplica os princípios de sua agenda historiográfica da arte, que volta atenção decididamente à "esfera pública" ao focar sobre museus, exposições e agentes que gestam e organizam essas instituições e eventos.

\footnotetext{
* Universidade Federal do Rio de Janeiro, Programa de Pós-graduação em Sociologia e Antropologia, Av. Pedro Calmon, 550 - Cidade Universitária da Universidade Federal do Rio de Janeiro, Rio de Janeiro - RJ, CEP 21941-901, Brasil. talissonmelo@yahoo.com.br

(iD) https://orcid.org/0000-0002-1456-0215
} 
Ampliando seu panorama para várias instituições durante amplo arco histórico e em várias cidades (Paris, Londres, Nova York, Amsterdã, Lodz, Boston, Buenos Aires, entre outras), Lorente desenrola vetores de negociações e disputas, repletas de dilemas não resolvidos e polêmicas, e que são mediatizados pela imprensa. Essas complicadas negociações se referem às missões/especialidades dos museus - como ser "museu de arte nacional ou de arte contemporânea?" (Lorente, 2008, p. 83), e ser "museu de arte moderna ou de arte contemporânea?” (Lorente, 2008, p. 254) -, e mesmo seus nomes não são irrelevantes, como o demonstra na sua análise, são "chaves para seguir os de como foram sendo tecidas as interinfluências culturais que moldaram suas identidades", sendo esses termos polissêmicos, ambíguos e mutantes, sem haver estabelecido um conceito museológico consensual de "arte contemporânea".

Enquanto Lorente propõe pensar os museus como formulações institucionais que atuam como paradigmas para formação de espaços e eventos em que a produção artística e seus públicos se encontram, mediados por suas missões museológicas, interpretações da arte e da sociedade, a socióloga Nathalie Heinich, por meio de sua "abordagem sociológica pragmática às artes", considera a noção de "arte contemporânea” como uma categoria sócio-estética, um novo paradigma artístico que começa a surgir nos anos de 1960, quando uma mudança paradigmática anterior ainda não havia sido completamente assimilada pela cultura popular ${ }^{2}$ - do paradigma da arte clássica para o da arte moderna ${ }^{3}$.

Para Heinich, o paradigma da arte contemporânea demandaria que artistas ultrapassassem “os limites do senso comum, não da figuração clássica, como no caso da arte moderna, mas da própria noção de arte, inclusive a exigência moderna de um vínculo entre a obra e a interioridade do artista" em que sua principal transgressão reside no fato de que "a obra de arte já não consiste exclusivamente no objeto proposto pelo artista, mas em todo o conjunto de operações, ações, interpretações etc. provocadas por sua proposição" (Heinich, 2014, p. 377). Essa mudança de status da obra tem implicações na sua materialidade, espacialidade, temporalidade, e, consequentemente, nos modos de colecionar, conservar, restaurar, classificar, apresentar, avaliar e mediar suas produções.

\footnotetext{
${ }^{1}$ De acordo com Heinich, “a abordagem sociológica pragmática às artes se propõe a descrever o enlaçamento íntimo entre objetos e ações humanas a fim de entender todo o conjunto de estruturas (incluindo estruturas simbólicas, como representações e valores) que compele e organiza as relações com a arte" (2014, p. 374).

${ }^{2}$ Heinich faz uma comparação com a noção de paradigmas científicos proposta por Thomas Kuhn em The structure of scientific revolutions (1962), em que o termo "paradigma" designa "a organização geral das noções compartilhadas pelos cientistas em determinada época” (2014, p. 386).

3 As definições oferecidas por Heinich desses paradigmas sugere que "a arte clássica exige que o artista execute o modelo padrão de figuração, seja de forma idealizada ou realística", enquanto "a arte moderna exige que o artista expresse sua interioridade, o que, muitas vezes, significa a necessidade de ultrapassar os padrões da figuração clássica ou até mesmo a própria figuração, como acontece no caso da arte abstrata” (2014, p. 376).
} 
Trazendo questões novas, como uma intrínseca camada discursiva que enfatiza o papel de instâncias mediadoras - "Uma obra de arte contemporânea quase nunca existe sem um texto, assinado ou não, escrito pelo próprio artista ou, melhor ainda, por um especialista, um crítico ou curador" (Heinich, 2014, p. 379).

As mediações de arte que determinam a inclusão ou não de um fenômeno para o interior da categoria arte contemporânea são compostas por espaços, coisas, pessoas, palavras, imagens, números, instituições e "as representações mentais específicas às várias categorias de atores" (Heinich, 2014, p. 380) ${ }^{4}$. No interior de sua agenda por uma sociologia pragmática da arte, Heinich afirma que "indivíduos que agem como intermediários no mundo da arte, através de publicações, exposições, disseminação, comentário, e estruturação material e mental, mais que obras e artistas, e espectadores, são um escopo perfeito para investigação sociológica" (Heinich, 2012, p. 701 - tradução do autor).

A partir dessa perspectiva, abordo neste artigo as mediações da arte contemporânea no Brasil, identificando processos, instituições e agentes envolvidos na emergência e consolidação de um novo paradigma entre os anos de 1960 e começo dos 1980, considerando as interrelações do universo artístico com outros elementos do contexto histórico nacional, marcado por um regime político ditatorial-militar. Enfoco a análise sobre a trajetória de Walter Zanini (-2013), crítico e historiador de arte, museólogo e professor, cujo nome sobressai na historiografia da arte brasileira tanto por ter dirigido o Museu de Arte Contemporânea da Universidade de São Paulo por 15 anos desde sua inauguração, em 1963, e por ter sido o primeiro a ocupar o cargo de curador geral da Fundação Bienal de São Paulo, de 1980 a 1983, encabeçando os projetos para as $16^{\mathrm{a}}$ e $17^{\mathrm{a}}$ edições da Bienal Internacional de São Paulo (ocorridas em 1981 e 1983, respectivamente); quanto por ter desempenhado papel ativo e profícuo na produção dessa mesma historiografia, escrevendo textos e organizando compilações em livros que abordam a produção artística no país em diferentes contextos históricos, com destaque para "História Geral da Arte no Brasil" (1983), em dois extensos volumes que cobrem amplo panorama de realizações, desde o período pré-colonial à sua atualidade, incluindo contribuições de demais especialistas sobre "arte popular", "arte índia", "arte africana e afro-brasileira" e "desenho industrial".

\footnotetext{
${ }^{4}$ Heinich também retoma o conceito bourdieusiano de autonomia dos campos para entender a "a existência atual de numerosos atores dedicados à seleção, circulação e avaliação de obras de arte", que advém da maior necessidade de mediação na medida em que a arte contmeporânea se torna "mais independente das regras ou expectativas ordinárias" (2014, p. 380).
} 


\section{QUAL ARTE? QUAL BRASIL? TRANSIÇÕES E UM AINDA-NÃO-LUGAR}

O cientista político Adriano Nervo Codato (2005), ao propor um modelo de história política para análise da transição da ditadura militar (assignada ao período de 1964 a 1989) à democracia no Brasil, identifica o desenrolamento de fases em que o regime se transforma, "num processo pendular, em que se revezaram períodos de maior e menor violência política" (Codato, 2005, p. 84). No esquema cronológico oferecido por Codato, a redemocratização se dá em três fases: (i) "transformação do regime ditatorial militar" que abarcou o governo do General Ernesto Geisel, de sua posse em 1974, anúncio de política de modificação do regime com propósito de promover uma distensão dos controles políticos militares impostos à sociedade civil, até revogação do Ato Institucional de número 5 (de 1968); (ii) uma fase de desagregação do regime, durante o governo do General João Figueiredo, de 1979, marcado pela promulgação da Lei da Anistia Política, até 1985, quando da vitória de oposição na eleição presidencial promovida pelo Colégio Eleitoral, e posse de José Sarney; (iii) e uma transição sob tutela militar para o regime liberal-democrático, durante o governo Sarney (de 1985 a 1989), quando se deram reestabelecimento de eleições diretas para Presidência da República, promulgação da nova Constituição, e campanha para as eleições presidenciais diretas, com vitória de Fernando Collor de Mello, empossado no ano seguinte.

No modelo de análise da transição que Codato propõe, chama atenção para as interações entre as Forças Armadas, o Estado e a sociedade; compreendendo o "Estado" como composto por feixes de instituições, organismos, aparelhos e agências burocráticas conectados às relações hierárquicas de diversos centros de decisão e articulações concretas destes com grupos sociais; bem como sendo a "sociedade" entendida a partir de sua estrutura produtiva e de classes resultante de um padrão específico de desenvolvimento capitalista (Codato, 2005, p. 89). Nesse âmbito de interrelações é que proponho pensar a emergência e consolidação da arte contemporânea no Brasil em democratização, identificando a posição de agentes culturais intermediários fundamentais nesses processos dentro de instituições públicas, sendo suas concepções de arte e cultura vinculadas a políticas culturais que fizeram instituições, programas de fomento, uma historiografia, e acumularam poder de mise-en-scène de determinadas linguagens artísticas em detrimento de outras. Ao focar sobre a atuação de Walter Zanini no interior desse contexto de transformações em que foi agente fundamental para estabelecimento de espaços para produção, reflexão, circulação e mediação da arte contemporânea, me pergunto qual concepção de arte dava base e norte a suas 
iniciativas, e como atuava de sua posição institucional e burocraticamente vinculada ao Estado (via Universidade), ao setor empresarial-industrial (via Fundação Bienal), e aos setores criativos e intelectuais.

\section{ATIVISMO INSTITUCIONAL - UM LUGAR PARA A ARTE CONTEMPORÂNEA}

Em duas teses defendidas recentemente, as pesquisadoras Izabela Pucu (2017) e Fabrícia Jordão (2018) abordam o papel das instituições artísticas como espaço de convergência da produção, mediação crítica, circulação e construção de públicos para a arte contemporânea no país - embora traçando marcos temporais distintos e enfocando instituições, eventos e agentes sociais específicos. Ambas, ao tratarem do contexto de democratização experimentado entre meados dos anos de 1970 e final dos 1980, retomam várias iniciativas levadas a cabo no âmbito institucional das artes visuais e que contribuíram na consolidação de um contexto de criação prática, teórica e crítica, difusão e socialização mais ligada àqueles agentes que se dedicavam às linguagens contemporâneas ou se identificavam com estratégias das chamadas neo-vanguardas emergentes a partir dos 1960 (Martins, 2013); e essa dinâmica se dava em contraponto aos anos de maior repressão e desarticulação entre agentes artísticos politizados e seus públicos, que se seguiram ao golpe civil-militar de 1964 e o Ato Institucional número 5, de final de 1968, por intervenção do regime nos canais de promoção e difusão da produção cultural; e com a atuação do Conselho Federal de Cultura, de viés patrimonialista (Maia, 2012).

Pucu narra etapas de um "deslizamento da crítica institucional para o fazer instituição como crítica, [que] contribui também com a mudança de posição de todo o campo da arte no espaço social", cuja genealogia é indicada como tendo um ponto importante de partida em realizações do período de ditatorial:

Do paradigma fundado no protagonismo e na iniciativa do artista (Crítica Institucional) para uma outra visão mais abrangente, onde o artista, o ativista entre outros atores sociais colaboram na construção de imaginários sociais alternativos ou na democratização das instituições (Práticas Instituintes). (Matoso, 2015 apud Pucu, 2017)

Traçando uma linha temporal de ações que evidenciam esse "deslizamento" para práticas instituintes desenvolvidas no Brasil, Pucu indica "(contra)exposições" promovidas por membros do Grupo Rex (1966-1967) e a intervenção do coletivo Seis Mãos durante palestra do crítico italiano Achille Bonito Oliva na Galeria Saramenha, no 
Rio de Janeiro, em 1986, como exemplos de dois momentos da crítica institucional local - o primeiro fazendo crítica em direção a processos de legitimação da produção artística por meio de instituições como a crítica e os salões, o segundo se dirigia também a essas instâncias, porém, abarcando e mirando as relações dessas com o mercado de arte que emergia e se internacionalizava desde meados dos anos 1970. Um dos principais exemplos de prática instituinte apresentado por Pucu é o da atuação do crítico e curador Frederico Morais no Museu de Arte Moderna do Rio de Janeiro, entre 1967 e 1973, especialmente com o emblemático projeto Domingos da Criação, que organizou enquanto diretor de cursos do museu no ano de 1971.

Destaco o caso anterior pois é evocado no trabalho de Fabrícia Jordão, ao inserir o projeto "Área Experimental", também vinculado ao trabalho de Morais no MAM do Rio, num conjunto de exemplos do que conceituou como "ativismo institucional", partindo da hipótese de que um novo tipo de ativismo artístico se desenvolvia durante a redemocratização no país, baseado no trabalho e nas ideias de agentes produtores e mediadores das artes visuais que logravam inserção na estrutura institucional promovida pelo estado autoritário:

Ao longo dos anos 1970, a precariedade das instituições do meio de arte, bem como o reduzido interesse do mercado em promover e difundir as produções associadas às linguagens contemporâneas fundamentaram uma percepção - por parte de artistas vinculados a essa vertente - de que era preciso criar estratégias para assegurar uma dimensão pública, institucionalizar e inscrever social e historicamente suas produções. Esse entendimento está diretamente relacionado a conformação de uma nova sensibilidade ético-político-estética no meio das artes visuais. Diferentemente da geração anterior, a qual vivia assombrada pelos fracassos, efeitos residuais e conflitivos da ideologia cepecista e pecebista, os artistas atuantes ao longo dos anos 1970 estabeleceram uma relação menos utópica e revolucionária com a arte em suas conexões com o âmbito político. A militância, o engajamento e a resistência cultural - nos sentidos estritos dos termos - cedem lugar para a atuação e a interferência concreta nos rumos do processo cultural, nas políticas de Estado e nas instituições públicas, em consonância com a crescente politização do espaço artístico, o sistema da arte e o papel de seus agentes e instituições são reexaminados criticamente. Esse processo foi acompanhado por uma redefinição do lugar social do artista e pela incipiente formação de uma identidade "artista contemporâneo", a qual, naquele momento, se associava aos artistas que buscavam intervir - estratégica e propositivamente - nos processos e instâncias que determinavam a conceituação, a formação, a produção, a circulação e a inscrição social de seus trabalhos. (Jordão, 2019)

Em sua tese (2018), Fabrícia Jordão examina em minúcias a transformação experimentada no circuito artístico brasileiro com o início do processo de abertura política, em 1974, no governo Geisel, e continuado com o governo de seu sucessor, o Presidente 
General Figueiredo, de 1979 até o fim do regime autoritário em 1985, com a posse da presidência por Tancredo Neves. Nessa tese, a mudança nas dinâmicas de relação entre o Estado e o campo das artes visuais é analisada através de descrição do aparelho estatal de políticas culturais, centrando-se em órgão do Ministério de Educação e Cultura, como o Conselho Federal de Cultura e seus parâmetros normativos e fiscalizadores, antes do processo de abertura, e novos valores e estratégias inseridos nas ações do governo através do estabelecimento de uma Fundação Nacional (a Funarte) para as artes visuais, o Instituto Nacional de Artes Plásticas (INAP), especialmente a partir de 1980, sob direção de Paulo Sérgio Duarte.

O trabalho de Fabrícia Jordão é crucial para uma observação nuançada das alterações do âmbito oficial da cultura que viabilizaram a emergência de uma série de ações que garantissem a viabilidade da emergência, institucionalização e profissionalização da arte contemporânea no país. Enfocando "estratégias para assegurar a dimensão pública" (Jordão, 2018, p. 141) da produção artística de linguagens contemporâneas, no sentido de agenciamentos entre artistas e mediadores que trabalharam no interior da estrutura oficial promovida pelo estado autoritário, potencializando suas intenções de "institucionalizar e inscrever social e historicamente suas produções" (Jordão, 2018, p. 8), e que estava coadunado a um processo mais amplo de rearticulação e empenho de setores progressistas na reorganização da sociedade e remodelação das esferas institucionais.

Desde sua inauguração, e especialmente com a sua continuidade, a Bienal de São Paulo foi central no curso do desenvolvimento de um campo artístico moderno brasileiro, com produção, reflexão e debates encontrando vias de alinhamento com tendências das artes de grandes centros. A disputa entre figuração e abstração aqueceu discussões entre críticos e artistas, a presença de determinadas obras conflui diretamente para o desenvolvimento de diferentes caminhos na pintura e na escultura brasileira que encontrou conformação singular no Concretismo e no Neoconcretismo. Com a promulgação do Ato Institucional número 5, de dezembro de 1968, intensificando a censura e a repressão do regime aos meios de comunicação, à expressão artística e liberdade de cátedra, o vínculos internacionais da Bienal levaram a irromper uma manifestação de denúncia transnacional acerca da situação do país, tendo sido o boicote à $10^{a}$ edição da Bienal, de 1969, um meio de fazê-la ressoar material e simbolicamente, pois algumas delegações nacionais se recusaram a enviar sua representação, e vários artistas e críticos assinaram o manifesto Non à la Bienal!, encabeçado pelo crítico francês Pierre Restany, quem estava incumbido de organizar uma sala especial para a mostra daquele ano, porém decidiu por abortar o projeto 
diante da prisão de Niomar Sodré, diretora de um jornal no Rio de Janeiro. Seguindo em atividade nos anos de 1970, os resultados de cada edição não apresentavam a mesma adesão de antes, e são específicos os exemplos de participações que alcançaram repercussão crítica, evidenciando uma situação de deslegitimação da instituição/evento.

Com o processo conciliatório de reabertura política, e mais intensamente com a necessária reformulação da instituição para manter-se de pé após o falecimento de Ciccilo, em 1977, é patente o empreendimento por parte de sua Fundação e realoca-la como instituição legítima e conectada às práticas e ideias atuais das artes visuais (Pereira, 2016). A primeira edição resultante desse processo, a $16^{a}$, de 1981, foi curada por Walter Zanini, nomeado em meados do ano anterior por acordo entre membros da Diretoria, do Conselho Administrativo e do Conselho de Arte e Cultura da Fundação. Zanini foi o primeiro a ocupar o cargo nomeado "curador geral", compreendendo funções específicas e um modus operandi que buscava intervir de maneira significativa na estrutura burocrática e diplomática que viabilizava a realização das mostras, considerando sua grande escala, escopo internacional, e demanda por periodicidade e atualização.

Nessa narrativa sobre um "ativismo institucional" desempenhado por determinados agentes do universo da arte contemporânea no Brasil, respondendo a e intervindo sobre condições específicas do contexto nacional em democratização, também dialogam com reconfigurações institucionais da arte em outros contextos, como os evidenciados por Jesús Pedro Lorente em sua história dos museus de arte contemporânea (2008). Iniciativas como a Art Workers Collition de Nova York, o programa de exposições Projects, curado por Pontus Hulten, e a exposição internacional Information, curada por Litch no MoMA em 1970; a criação do Centro de Arte Comunicación (CAYC), em Buenos Aires, e a própria criação do Centre Pompidou, forneciam fontes para experiências correlatas e coetâneas desse processo, e se articulavam a essa por uma rede de agentes e fluxos de ideias, imagens e proposições que circulavam cada vez mais. Walter Zanini também se destaca como agente de ampla inserção em redes transnacionais da arte contemporânea, e buscarei evidenciar esses intercâmbios também na seção seguinte deste artigo.

\section{WALTER ZANINI E UMA CARTOGRAFIA INTERNACIONALISTA DA ARTE CONTEMPORÂNEA}

Ao buscar informações que pudessem me auxiliar na compreensão de origens sociais e trajetória formativa de Walter Zanini, previamente a seu cargo de professor e 
diretor de museu na USP, para pensar sobre seu interesse nas artes visuais e suas condições de relação com a arte contemporânea, o mais remoto que pude traçar é a hipótese que parte do seu contato com o tio, o pintor Mário Zanini (1907-1971).

Mário Zanini era filho de imigrantes italianos e se estabelecera no bairro do Cambuci, vindo a ser um dos membros fundadores do Grupo Santa Helena (1935), composto de operários e artesãos oriundos de cursos profissionalizantes do Liceu de Artes e Ofícios, em São Paulo (Cf.: Brill, 1984; Zanini, 1991; Freitas, 2011). E que se afirmava no contexto local ao longo dos anos de 1930 e 1940, participando das exposições Família Artística Paulista, organizadas por Paulo Rossi Osir (1890-1959), de formação europeia, chegado ao Brasil em 1920. A erudição desses integrantes, da classe trabalhadora e pequena-burguesia, dava-se pelo contato com intelectuais como Sérgio Milliet (1898-1966), Paulo Mendes de Almeida (1905-1986) e Mário de Andrade (1893-1945), além de Osir, e pela frequentação a bibliotecas desses homens ou aos poucos acervos públicos que tinham acesso (Quintana, 2018, p. 9-10), canais de encontro com ideias, imagens e técnicas da arte moderna de centros europeus. Sua produção se desenvolve em diferentes fases nas décadas seguintes, e como parte desse processo, o pintor compunha sua biblioteca, com volumes de livros e revistas dedicados à arte grega, ao Renascimento, à pintura italiana das primeiras décadas do século XX, até muralismo mexicano, entre várias antologias e biografias majoritariamente voltadas à pintura (Quintana, 2018, p. 41-44).

Dessas referências, o jovem Walter Zanini ${ }^{5}$ pôde tirar proveito em sua formação, do contato com o tio, sobre quem dedicou um de seus livros (ZANINI, 1991), dentro da sua interpretação sobre o Grupo Santa Helena, como vertente da arte moderna que passava ao largo daquela celebrada pela Semana de 1922, e posteriormente marcada por manifestos e mais ampla visibilidade.

Na São Paulo de final dos anos 1940 e início dos 1950 (quando se inauguravam os principais museus de arte do país, bem como a própria Bienal Internacional de São Paulo, em 1951), Walter Zanini frequentava dois cursos de graduação que completou em 1951, Economia pela USP e Jornalismo pela Cásper Líbero. Como crítico de arte para os jornais Tribuna da Imprensa e O Tempo se dedicava assim que recém-formado, aplicando seus conhecimentos sobre artes plásticas e encontrando posição privilegiada para vivenciar o contexto de ebulição artística moderna na cidade.

\footnotetext{
${ }^{5}$ Bem como seu irmão, Ivo Zanini (1929-2013), que veio se tornar crítico de arte de destaque, contribuindo largamente com textos para a Ilustrada da Folha de São Paulo nos anos de 1960 e 1970, foi membro da $\mathrm{ABCA}$, e compôs júris de seleção, premiação para vários certames.
} 
Os desdobramentos de sua trajetória, movida pelos interesses manifestos nesses anos, aprofundou-se em direção à história da arte, arqueologia e museologia. Embarcava para Paris com bolsa do governo francês, concluindo nova graduação, além de cursos paralelos em outras instituições como a École du Musée du Louvre, entre outras, quando também entre em contato com vários agentes mediadores do universo artístico moderno que viriam a ser elos para o desdobramento de suas atividades, posteriormente, no Brasil, em várias frentes e de franca internacionalização ${ }^{6}$. Em Paris, além do contato com seus orientadores de mestrado e doutorado, André Chadtell e Jean Cassou, que o levaram ao contato com o International Committee of Museums, o Comité International d'Histoire de l'Art, e com suas atuações como diretores de museus e escolas; Zanini também entrou em contato direto, com o movimento artístico Phases ${ }^{7}$, que se constituía de atividades integradas por poetas, artistas e escritores, em publicações, livros, exposições e reuniões. Na Europa, também vivenciou por curtos períodos do ambiente acadêmico e artístico de Londres e Roma.

De volta ao Brasil, em 1962, com especialização rara no contexto local, Zanini encontrou-se com a oportunidade de, no ano seguinte, assumir cargo na USP que viabilizaria sua atuação em várias frentes, como professor em museologia e história da arte, diretor do então inaugurado MAC-USP (de 1963 até ser exonerado da diretoria em 1978), onde aplicava princípios museológicos de conservação e restauração, aquisição e catalogação de obras de arte, e uma missão de arregimentar artistas jovens, que experimentavam linguagens e meios expressivos emergentes.

Como demonstra a pesquisadora Cristina Freire (2014), para uma memória coletiva das artes visuais no Brasil dos anos 1960 e 1970, o MAC-USP significou um "laboratório de criação para artistas" (Cf.: Sulzbacher, 2010; Palma, 2014; Carvalho, 2014), o que se testemunha por seu acervo de arte conceitual, constituído majoritariamente de obras adquiridas a partir de eventos que tinham lugar no museu. Porém, para o desenvolvimento da curadoria de arte contemporânea no país, e para a trajetória de Walter Zanini especificamente (Cf.: Tejo, 2017), tratou-se de "um grande experimento para seu primeiro diretor que desenvolveu no Museu, de maneira dialógica e colaborativa, seus projetos", por

\footnotetext{
${ }^{6}$ Abordo com detalhes a formação e as redes de socialização de Walter Zanini em minha tese de doutorado, enfatizando sua atuação como diretor do MAC-USP e curador geral das $16^{\mathrm{a}}$ e $17^{\mathrm{a}}$ Bienais Internacionais de São Paulo (Souza, 2020).

${ }^{7}$ Que se dava em torno da revista de mesmo nome criada em 1957, e editada até 1975. Artistas e intelectuais da Europa e da América Latina, residindo em Paris, entre esses anos, tomaram parte nos encontros, publicações e exposições do movimento, geralmente associados ao surrealismo, e a neo-vanguardas como pop art, grupo Cobra. Nesta cidade, por iniciativa de Zanini, como grupo Austral, no início dos 1960, estimulando intercâmbio entre artistas no país, e organizando exposições coletivas de integrantes, como a que teve lugar no MAC-USP em 1967.
} 
meio dos quais logrou "instaurar parâmetros acadêmicos e críticos, bem como princípios curatoriais e museológicos que seriam decisivos para a inserção das práticas artísticas contemporâneas no contexto dos museus e das exposições de arte no Brasil" (Freire, 2014: 20). Freire ressalta ainda três aspectos centrais para compreender o modus operandi de Zanini a partir do MAC-USP: o museu como lugar de criação, estimulando pesquisas experimentais interdisciplinares (ou Intermedia, para retomar o conceito articulado por Filliou), e "a noção de rede como princípio operativo" (Freire, 2014: 20) - que também encontrava ressonância em outro conceito elaborado mais tarde também por Filliou, a Eternal Network (Brecht \& Filliou, [1989] 1995), como uma comunidade de interrelações sem fronteiras.

A rede de relações pessoais, profissionais e institucionais que Zanini foi tecendo a partir da e para a constante ativação e reformulação do Museu, contou com projetos, associações, instituições e exposições. Algumas iniciativas de Zanini para estabelecer redes tiveram existência mais curta (como a Associação de Museus de Arte do Brasil - AMAB, 1966-1977), ou não saíram do plano projetual (caso do Trem de Arte que percorreria o Estado com exposições itinerantes do acervo do Museu, que chegou a ser esboçado por Lina Bo Bardi, 1968, mas não chegou a ser apoiado e financiado para que se concretizasse; e uma Associação dos Museu de Arte da América Latina, que propôs e defendeu durante a Conferência dos Diretores de Museus de Arte do Hemisfério, ocorrida no Metropolitan Museum de Nova York, em 1972, por iniciativa do Center for Inter-American Relations, que não encontrou viabilidade dentro da agenda estadunidense em plena Guerra Fria).

Outras iniciativas vieram a configurar robustos pontos de convergência nos processos de profissionalização acadêmica votado às artes no país, e que ainda hoje são fundamentais, como o Comitê Brasileiro de História da Arte (fundado em 1972, o qual dirigiu desde a fundação até 1998 - vinculado ao Comité International d'Histoire de l'Art de cujos congressos Zanini participava desde sua estada em Paris) e a Associação Nacional de Pesquisadores de Artes Plásticas - fundada em 1985, junto ao CNPq e a partir da criação do doutorado em artes na Escola de Comunicação e Artes da USP, chefiado então por Zanini (Cf.: Peccinini, 2017).

O “perfil de Walter Zanini” traçado pela historiadora da arte Annateresa Fabris (2009a; 2009b) evidencia a capacidade articuladora de redes e estimuladora de projetos, que atribui à atuação de Zanini uma figura de nó congregador, pessoa que acumulou posições de poder decisório nas principais frentes mediadoras do universo artístico institucional do país, dirigindo museus, associações de museus, projetos de criação de departamentos 
acadêmicos, cursos e associações de pesquisa. Daqui em diante, restringirei minha abordagem de sua atividade ao que se refere à promoção e institucionalização de linguagens artísticas contemporâneas, identificando nesse âmbito seu interesse específico sobre a relação entre arte experimental, Intermedia e novos meios de comunicação.

O principal resultante do esforço de Zanini em estimular a criação artística de jovens por meio do suporte material e institucional do MAC-USP foi a série de exposições Jovem Arte Contemporânea, realizadas anualmente entre 1967 e 1974, com base nas mostras bianuais Jovem Desenho Nacional (1963 e 1965) e Jovem Gravura Nacional (1964-1966), convergindo-as em programa único, as $J A C$, que se abria cada vez mais para experimentações com qualquer meio de interesse dos artistas (ver: JAREMTCHUK, 2013). Ao ponto que as edições realizadas entre 1971 e 1974 contaram com intensa atuação de artistas vinculados à arte conceitual e de Intermedia, com destaque para Donato Ferrari (Guardiagrele, Itália, 1933) ${ }^{8}$, Regina Silveira (Porto Alegre, 1939) e Julio Plaza.

O casal de artistas Silveira e Plaza regressava à São Paulo em 1973, após período de alguns anos lecionando na Universidad de Puerto Rico no Campus de Mayagüez (desde 1969), contexto cosmopolita em que tiveram contato com mais artistas vinculados à arte contemporânea de vertentes conceitualistas. Plaza organizou a exposição Creación/Creation em 1972, uma das pioneiras no uso da rede postal para recebimento de obras de artistas de vários países (foram 79 participantes). Ambos começaram a lecionar na FAAP e na ECAUSP, intensificando contato que já mantinham com Zanini há alguns anos, também passando a colaborar em seus projetos no MAC-USP. Dessa colaboração, Plaza pôde organizar mais uma exposição baseada no uso dos correios para a recepção de obras de artistas de vários países, assim se deram a Prospectiva 74 e a Poéticas Visuais, em 1974 e 1977, respectivamente (Cf. Binnie, 2017), cuja ampliação em número de participantes de uma para outra resultava do aumento da lista de contatos da rede de arte postal que vinha articulando desde seu contato com artistas da Nova Poesia na América do Sul.

Outras iniciativas encontraram solo propício para seu desenvolvimento por meio dos correios no MAC-USP. Zanini aceitava a proposta do artista Angelo de Aquino (Belo Horizonte, 1945-2007), para expor obras de artistas conceituais com quem entrou em contato quando residia na Europa, por meio do evento NET concebido na Polônia, em

\footnotetext{
${ }^{8}$ Ferrari concluiu seus estudos na Accademia di Belle Arti de Roma em 1958, transferiu-se para o Brasil em 1960, expôs suas obras em exposições de galerias do Rio e de São Paulo. Em 1968 tornou-se diretor da Faculdade de Artes Plásticas da FAAP. Em colaboração com Zanini, na USP, foi responsável pela organização do Departamento de Artes Plásticas da ECA-USP. Nos 1970, fez experimentações com VT e participou das atividades do MAC-USP e do $1^{\circ}$ Encontro de Vídeo-Arte no MIS, em 1978. Foi membro do CAC da FBSP para a $16^{a}$ Bienal, curada por Zanini.
} 
1971 (Cf. Kemp-Welch, 2019), um dos pontos principais da rede de arte postal partindo do leste europeu, então ocorreu, em 1973, a mostra "Seis Artistas Conceituais" (Cf. Sayão, 2015). Além das mostras organizadas por Plaza, houve realizações relacionadas ao CAYC, como a exposição "Década de 70”, de 1976 (Cf. Paladino, 2015); as exposições propostas pelo artista colombiano Jonier Marín, "Papel e Lápis", de 1976, que também aconteceu no Museo de Arte Moderno de Bogotá, e a "Videopost", com trabalhos fortemente politizados, em 1977 (Cf. Sayão, 2015, p. 92-95).

Tomo essa última como fio para o diálogo direto entre a arte postal e a videoarte, visto que sua realização só foi possível pois, naquele ano, se estabelecia no MAC-USP um setor preparado para a realização de experiências com equipamento de vídeo, bem como sua apresentação, que começava a ser coordenado por Cacilda Teixeira da Costa, que organizou a mostra "Vídeo MAC", no final de 1977 - uma primeira mostra reunindo trabalhos em VT de artistas brasileiros/as que já trabalhavam com o meio desde anos anteriores e artistas que iniciavam suas experimentações a partir do estabelecimento do setor no Museu (Cf. Costa, 2003; Aguiar, 2007). A exposição era abrigada na proposta do Espaço B levada a cabo por Zanini ao longo daquele ano, como programação que 'loteava' o espaço expositivo e de laboratório do MAC-USP para abrigar projetos experimentais de artistas multimídia.

A partir de várias camadas de discurso produzidas e reproduzidas sobre a videoarte no Brasil, outros momentos indicam para a importância do MAC-USP como espaço de promoção dessa linguagem. Como vinda do artista Fred Forest (francês, 1933) para a XII Bienal de São Paulo, em 1975, quando realizou Passeio Sociológico pelo Brooklin, também gravado pela TV Cultura, e exibido no MAC-USP, assim trabalhos dos suíços Gerald Minkoff (1937) e Jean Otth (1940-2013). A partir dessa articulação, Zanini aglutinava esforços para viabilizar a tecnologia do V'T entre artistas que frequentavam o Museu, e convidando estrangeiros que trabalhavam com ela, como Antoni Muntadas (catalão, 1942).

Em 1974, Zanini estimula artistas no país a produzirem para participação na exposição internacional "Video Art" organizada por Suzanne Delehanty no Institute of Contemporary Art da University of Pennsylvania, que inauguraria em janeiro de 1975. Artistas atuantes no Rio tiveram acesso Sony portapack trazida da Califórnia pelo cineasta Jom Tob Azulay (Rio de Janeiro, 1941), que trabalhava como diplomata no período. Assim, Sônia Andrade, Fernando Cocchirale, Anna Bella Geiger e Ivens Machado exibiram no MAC e no ICA seus primeiros trabalhos em VT. 
A representação dos Estados Unidos para a Bienal daquele ano era composta pela mostra VIDEOART U.S.A. organizada pelo curador Jack Boulton, exibindo VTs de artistas fundamentais para o movimento de primeira onda das experimentações artísticas com a mídia. Eventos como exibições e debates ocorreram simultaneamente no MACUSP, que ocupava o mesmo prédio onde acontecia a Bienal. Essa aproximação também levou, em 1977, à exibição de vídeos realizados pelas brasileiras Rita Moreira e Norma Bahia em Nova York, que comporiam a Bienal em 1977, mas tiveram que se deslocar para o MAC-USP devido a condições técnicas específicas. No ano seguinte, contando com apoio de várias fontes, incluindo o MAC-USP, a TV Cultura, a Sony, e a Comissão de Artes Plásticas da Secretaria de Cultura, sob comando de Wesley Duke Lee (São Paulo, 1931-2010), e organização de Marília Saboya (que trabalhou com Cacilda Teixeira da Costa no setor de vídeo do Museu no anterior), teve lugar no Museu da Imagem e do Som o $1^{\circ}$ Encontro Internacional de Video-Arte de São Paulo, grande panorama que congregava realizações artísticas com base no VT, contando com trabalhos de 70 artistas. No catálogo do Encontro, texto introdutório de Zanini, Vídeo-arte: uma poética aberta, esse agente mediador fundamental para o desenvolvimento da videoarte no país, sistematizava as situações cruciais para o processo mesmo de consolidação dessa linguagem artística nacionalmente.

Em 1978, a diretoria do MAC-USP e de outros museus da Universidade foram alteradas por ordem do novo reitor. Zanini, afastado daquele cargo, transpôs seus esforços em prol da arte de novas tecnologias para outros âmbitos. Em 1979, na ECA-USP, organizou a mostra Multimedia Internacional, em colaboração com Silveira, Plaza e Ferrari (também professores na instituição) e de vários estudantes e artistas. Essa exposição era apresentada como uma sequência das que vinha realizando no MAC-USP enquanto seu diretor, baseado na chamada de envio de obras por correio, aberta a toda e qualquer proposta, reunindo trabalhos de cerca 240 participantes de 19 países.

Desde 1978, Zanini também manteve, até 1981, a Aster, uma espécie de centro de produção e reflexão sobre arte contemporânea que criou com Roberto Sandoval, Silveira, Ferrari e Plaza, como sócios, onde davam continuidade a seus projetos individuais e em colaboração, em que se incluía com destaque a experimentação com videoarte (MELLO, 2009).

$\mathrm{Na}$ narrativa acima elaborada sobre a formação e atuação de Walter Zanini, busquei colocar em relevo alguns elementos que ajudam a compreender os motivos que levaram a FBSP a nomear Zanini como a primeira pessoa a ocupar o cargo de curador geral criado em 1980. A demanda pela criação de um cargo como o de curadoria, sob diferentes termos e 
em diferentes perspectivas, pode ser rastreada historicamente por meio de debates internos à Bienal no desenrolar de suas edições pelo menos durante toda a década de 1970. Tanto na esteira de reações influenciadas pelo boicote internacional à edição de 1969, quanto por outros motivos, como de questionamentos relativos à centralidade da figura de seu fundador, o empresário e mecenas, presidente da FBSP, Francisco Matarazzo Sobrinho, até sua morte em 1977; ou às sucessivas alterações de um programa que muitas vezes era recebido com descrédito no meio artístico, e com grandes polêmicas. A FBSP, então presidida pelo empresário Luiz Villares, entrava na década de 1980 com o plano de se reformular, transformando-se em um centro cultural de atividades artísticas contínuas, para além da realização das Bienais. Esse projeto chamado por Villares de Utopia, foi negado por especialistas latino-americanos (incluindo brasileiros) quando da realização de um Encontro de Consulta, em outubro de 1980, que substituía a $2^{\text {a }}$ Bienal Latino-Americana de São Paulo - mesma ocasião em que o projeto de recorte regional foi cancelado, e sobressaiu a proposta de se estabelecer um ênfase na arte latino-americana para as Bienais Internacionais.

Entendo que a relação estabelecida por Zanini com tendências emergentes das linguagens artísticas contemporâneas trazidas e desenvolvidas para e no MAC-USP por artistas jovens e/ou emergentes, e alguns de recente consagração (para a qual o Museu teve papel importante), é o elemento chave para sua nomeação. Um segundo elemento seria a autoridade intelectual que construíra Zanini ao desempenhar simultaneamente tantas funções em posição de chefia, coordenação e direção, que trazia para sua figura boa parte do crédito que a FBSP então visava recuperar diante da comunidade artística nacional e internacional. Zanini também ostentava em seu currículo a potência de atração interesses e concretização de projetos de escala transnacional, como se vê pelas mostras no MAC-USP e a Multimedia Internacional, fator decisivo para a incumbência de organizador de um evento com a escala da Bienal.

De fato, Zanini conquistou algumas representações de países que não enviam obras para o certame desde as repercussões do boicote na virada para os 1970, como Finlândia, Suécia, Holanda e Dinamarca, que retornariam em peso a partir de 1983. Também propôs a formação de uma Comissão Internacional para a montagem do Núcleo $I$, de arte contemporânea, da $16^{\mathrm{a}}$ Bienal - entre seis integrantes, três latino-americanos: além do próprio Zanini, Helen Escobar, artista e gestora de museus no México, e Milan Ivelic, chileno, crítico e historiador de arte. Mas Zanini também trazia consigo uma interpretação singular do estado atual da arte, que se articulava diretamente com tendências muito em 
voga a partir da arte conceitual e da arte de novos meios, e obras de artistas vinculados a tais movimentos e estratégias expressivas tiveram lugar privilegiado no seu projeto curatorial, tanto na $16^{\mathrm{a}}$ quanto na $17^{\mathrm{a}}$ edições.

Agora retorno à presença da mail art na $16^{\mathrm{a}}$ Bienal, exatamente porque considera que nela culminaram vários encaminhamentos experimentados por Zanini em seu programa museológico para o MAC-USP. A seção Arte Postal, integrada ao Núcleo I, foi cocurada por Julio Plaza ${ }^{9}$, ocupando um terço do segundo andar do Pavilhão, com quase 500 obras recebidas de diversos países.

Essa exposição concretizava projetos propostos à FBSP (e ao Ciccillo em particular) desde final dos anos 1960 por especialistas como Pierre Restany (para a X Bienal, de 1969), René Berger (para a de 1971), e Vilém Flusser (para a de 1973) que não se concretizaram, e a proposta de temas elaborados a partir de pesquisa sobre práticas contemporânea, que deram norte a parte da XIV Bienal, em 1977.

A abordagem da arte de novos meios ou multimídia, conceitual e experimental que era fomentada pelas realizações do MAC-USP nos 1970, através do projeto de Zanini como curador da Bienal em 1981, expandia seu alcance para além da seção do Museu que ocupava o terceiro andar do Pavilhão, tomando-o quase que completamente, pois era a base do projeto curatorial da $16^{\mathrm{a}}$ edição.

\section{CONSIDERAÇÕES FINAIS - E QUANDO A UTOPIA ENCONTRA LUGAR?}

A 16ª edição da Bienal Internacional de São Paulo, inaugurada em 16 de outubro de 1981 e encerrada em 20 de dezembro do mesmo ano, foi uma grande exposição de artes visuais organizada pela Fundação Bienal de São Paulo (FBSP), tendo Walter Zanini à frente de seu Conselho de Arte e Cultura (CAC). Esse evento acabou configurando-se no período como ponto de convergência de negociações, disputas, expectativas e frustrações para numeroso grupo de agentes do universo artístico brasileiro. Aguardada e avaliada como espécie de termômetro ou bússola, a $16^{\text {a }}$ Bienal indicaria o estado das coisas na entrada para uma nova década, viabilizando um balanço de carências, riscos, potências e tendências (entre emergências, institucionalizações e dissoluções de linguagens, atitudes e categorias).

Essas avaliações diziam respeito não somente à própria instituição Bienal de São Paulo ou às Bienais como modelo de circulação internacional da arte contemporânea; não

\footnotetext{
9 Para a $17^{a}$ Bienal, Plaza organizou uma seção intitulada Videotexto (com patrocínio da TELESP), em que foram mostradas obras de artistas de diferentes países (Brasil, Espanha, Canadá, Itália, Israel e Grécia), com base em vídeo, imagem via satélite, computador e TV a cabo.
} 
só às artes visuais em São Paulo ou no Brasil, ou na América Latina, mas também como fenômeno compreendido como internacional, 'universal'; e tampouco restrito aos caminhos da inventividade artística de cada nação atual na esfera das relações transnacionais que compunham esse 'universo da arte contemporânea', permitindo ensaios de compreensão sobre a política nacional, regional e a geopolítica global, a abrangência do mercado na vida, os rumos da existência humana no planeta...

O projeto curatorial de Zanini para a $16^{a}$ Bienal se baseava no critério de "analogia de linguagens" para classificar e organizar as obras recebidas no espaço expositivo. Diante de condicionantes institucionais relacionadas às representações oficiais dos países participantes pela via diplomática, nem todos os envios levavam o projeto em conta, e Zanini sinalizou a divergência de modo explícito, reservando um espaço específico para essas obras, que chamou de "vetor Divergentes". O "Núcleo I", de arte contemporânea, ocupou parte do primeiro andar do Pavilhão, e todo o segundo andar, sendo um terço deste reservado para a mostra de Arte Postal, co-curada por Julio Plaza. Nessa seção, obras de artistas de diferentes países conviviam no mesmo percurso, em que a relação com "novos meios" ou abordagem crítica e experimental de "meios tradicionais" era a dimensão das obras que orientava aproximações entre elas.

Além das mais de 500 peças recebidas pelos correios, todas aceitas para exibição, vindas de diversos países por artistas que compunham a Eternal Network da mail art, a representação brasileira, totalmente concentrada no "Núcleo I", trazia a seleção de artistas a convite do CAC, em que se vê a estrita vinculação do projeto de Zanini com tendências específicas das linguagens artísticas contemporâneas, com Tunga, Anna Bella Geiger, Ivens Machado, Carlos Fajardo, Carmela Gross. E a instalação Bruja de Cildo Meireles, partia de uma vassoura apoiada na parede de um canto do segundo andar, mas suas cerdas eram feitas de fios parecidos com barbantes que se desenrolavam pelo chão, intervindo em outros espaços do Pavilhão, através do labirinto de obras que compunha o núcleo. O projeto de Zanini seleva o comprometimento da principal instituição promotora de exposições internacionais do país com o novo paradigma, o da arte contemporânea, com sua base internacionalista/universalista, gestada no MAC-USP ao longo dos anos de 1970 e através das redes de relações que Zanini pode tecer no período, transplantando boa parte dela para a $16^{\mathrm{a}}$ e a $17^{\mathrm{a}}$ Bienais, como curador.

Recebido para publicação em 08 de maio de 2020.

Aceito em $1^{\circ}$ de agosto de 2020. 


\section{REFERÊNCIAS}

AGUIAR, Carolina A. Videoarte no MAC-USP: o suporte de ideias nos anos 1970. Dissertação (mestrado em Estética e História da Arte) MAC-USP, São Paulo, 2007.

BINNIE, Mari R. Prospectiva 74 \& Poéticas Visuais: The International Horizon of 'Anartistic' Print Experimentation. In: Caiana, n.2, 2017.

BRECHT, George; FILLIOU, Robert. [1989] The eternal network. In: WELCH, Chuck (org.) Eternal Network: A Mail Art Anthology. Calgary, Canadá: University of Calgary Press, 1995.

BRILL, Alice. Mário Zanini e seu tempo. São Paulo: Perspectiva, 1984.

CARVALHO, Ananda. Redes curatoriais: procedimentos comunicacionais no sistema da arte contemporânea. Tese (doutorado em Comunicação e Semiótica) PUC-SP, São Paulo, 2014.

CODATO, Adriano. Uma história política da transição brasileira: da ditadura militar à democracia. Rev. Sociol. Polit. 2005, n.25, pp.83-106.

COSTA, Cacilda Teixeira da. Videoarte no Mac. In: MACHADO, Arlindo (org.). Made in Brasil: três décadas do vídeo brasileiro. São Paulo: Itaú Cultural, 2003.

FABRIS, Annateresa. Walter Zanini: O construtor do MAC-USP. In: Atas do XXIX Colóquio do Comitê Brasileiro de História da Arte - Historiografia da Arte no Brasil: um balanço das contribuições recentes - Homenagem a Walter Zanini, 2009a, pp.12-20.

Perfil de Walter Zanini. In: Atas do XXIX Colóquio do Comitê Brasileiro de História da Arte - Historiografia da Arte no Brasil: um balanço das contribuições recentes Homenagem a Walter Zanini, 2009b, pp.1-2.

FREDRICKSON, Laurel J. Life as Art, or Art as Life: Robert Filliou and the Eternal Network. In: Theory, Culture \& Society, setembro, 2018, pp.1-29.

FREIRE, Cristina (org.). Walter Zanini: Escrituras críticas. São Paulo: Annablume, 2013.

FREIRE, Cristina. Museus em rede: A dialética impecável de Walter Zanini. In: Art Journal, Vol. 73, N. 2, verão, 2014, pp.20-45.

Arte postal: comunicação marginal. In: FREIRE, Cristina. Poéticas do processo: arte conceitual no museu. São Paulo: Iluminuras/MAC-USP, 1999. pp.76-86.

FREITAS, Patrícia. O Grupo Santa Helena e o universo industrial paulista (1930-1970). Dissertação (mestrado em História) UNICAMP, Campinas-SP, 2011.

GILBERT, Zanna. Genealogical Diversions: Experimental Poetry Networks, Mail Art and Conceptualisms. In: Caiana, N.4, 2014. 
HEINICH, Nathalie. Práticas da Arte Contemporânea: Uma Abordagem pragmática a um novo paradigma artístico. In: Sociologia \& Antropologia, vol. 04 n 2, 2014, p 373-387.

HEINICH, Nathalie. Mapping intermediaries in contemporary art according to pragmatic sociology. In European Journal of Cultural Studies, v.15(6), 2012, pp. 695-702.

JAREMTCHUCK, Dária. MAC do Zanini: o museu crítico do museu. In: OLIVEIRA, E. D. e COUTO, M. F. M. (org.). Instituições da arte. Porto Alegre: Zouk, 2013.

JORDÃO, Fabrícia. As atuações e contribuições institucionais e artistas e intelectuais no campo das artes visuais: durante o período da redemocratização brasileira (1974-1989). Tese (doutorado em Artes Visuais) ECA-USP, São Paulo, 2018.

JORDÃO, Fabrícia. Ativismo Institucional. (verbete) In: Revista Arte ConTexto Reflexão em Arte, v.6 n.15, 2019. Disponível em: http://www.artcontexto.com.br/portfolio/ativismo-institucional fabricia-jordao/

KEMP-WELCH, Klara. NET: an open proposition. In: e-flux Journal, N.28, 2019, disponível em: https://www.e-flux.com/journal/98/256870/net-an-open-proposition/

LOBETO, Claudio. Entre la acción social y las prácticas estéticas: El movimiento de Video en Santiago de Chile, San Pablo y Buenos Aires (1980-2000). Tese (doutorado em Letras) Universidad de Buenos Aires, 2009.

LORENTE, Jesús P. Los museos de arte contemporáneo: noción y desarrollo histórico. Gijon, Espanha: Ediciones Trea, 2008.

MAgalHães, Ana G. A Bienal de São Paulo, o debate artístico dos anos 1950 e a constituição do primeiro museu de arte moderna do Brasil. In: Museologia \& Interdisciplinaridade, Vol.IV, N.7, 2015, pp.112-129.

MAIA, Tatyana. Os cardeais da cultura nacional: o Conselho Federal de Cultura na ditadura civil-militar (1967-1975). São Paulo: Itaú Cultural (Rumos Pesquisa) / Iluminuras, 2012.

MARTINS, Sérgio. Constructing an avantgarde: Art in Brazil, 1949-1979. Cambridge-MA: MIT Press, 2013.

MATHIAS, S. A militarização da burocracia: a participação militar na administração federal das Comunicações e da Educação, 1963-1990. São Paulo: Ed. UNESP, 2004.

MELLO, Christine. Vídeo no Brasil 1950-1980: novos circuitos para a arte. In: Arte y política de identidad. Múrcia, Espanha: Publicaciones Universidad de Murcia, 2009, pp.185220.

PALADINO, Luiza. Conceitualismos em trânsito: intercâmbios artísticos entre Brasil e Argentina na década de 1970 - MAC USP e CAYC. Dissertação (mestrado em Estética e História da Arte) MAC-USP, 2015.

PALMA, Adriana. Invenções museológicas em exposição: MAC do Zanini e MASP do casal Bardi. Dissertação (mestrado em Estética e História da Arte) MAC-USP, São Paulo, 2014. 
PECCININI, Daisy. Crônicas dos primeiros tempos da ANPAP. In: Anais do $26^{\circ}$ Encontro da ANPAP - Memórias e Inventações, Campinas-SP, 2017.

PEREIRA, Verena. A gestão das artes visuais através da Bienal de São Paulo: pode entrar sem medo que é só arte. Tese (doutorado em artes visuais), Unicamp, 2016.

PINHEIRO, M. Ditadura: o que resta da transição. São Paulo: Boitempo, 2014.

PUCU, Izabela. Arte como trabalho (e vice-versa). Tese (Doutorado em Artes) Escola de Belas Artes da Universidade Federal do Rio de Janeiro, 2017.

SAYÃO, Bruno. Solidariedade em Rede: Arte postal na América Latina. Dissertação (mestrado em Estética e História da Arte) MAC-USP, São Paulo, 2015.

SCHOEREDER, Caroline. X Bienal de São Paulo: sob os efeitos da contestação. Dissertação (mestrado em Artes) ECA-USP, São Paulo, 2012.

SOUZA, Tálisson. Cartografias estéticas entre mediação e esfera pública: como a 'arte latino-americana' acontece? In DABUL, L.; GUERRA, P. De Vidas Artes. Porto: editora da Universidade do Porto, 2019.

Art vidéo, corps, espace public et télévision : les tranchées et les Institutions au Brésil et au Chili des années 1980. In: Artélogie, Paris, N. 8, junho, 2016, disponível em : http://cral.in2p3.fr/artelogie/spip.php?article444

As $18^{a}$ e $19^{a}$ Bienais Internacionais de São Paulo: Curadoria entre a prática e o debate no Brasil. Dissertação (mestrado em Artes, Cultura e Linguagens), IAD-UFJF, Juiz de Fora-MG, 2015.

QUINTANA, Lauci B. Mário Zanini, o pintor que lê: arte e biblioteca. Tese (doutorado em Estética e História da Arte) MAC-USP, São Paulo, 2018.

TEJO, Cristina. A gênese do campo da curadoria de arte no Brasil: Aracy Amaral, Frederico Morais e Walter Zanini. Tese (doutorado em Sociologia) Universidade Federal do Pernambuco, Recife, 2017.

ZANINI, Walter. Tendências da escultura moderna. São Paulo: Editora Cultrix, 1971.

[1978] Vídeo-arte: uma poética aberta. In: PECCININI, Daisy. Arte novos meios/multimeios: Brasil 70/80. São Paulo: FAAP, 1985.

Introdução. In: XVI Bienal Internacional de São Paulo - Geral. Catálogo de exposição. São Paulo: Fundação Bienal de São Paulo, 1981.

História Geral da Arte no Brasil. Vols. 1 e 2. São Paulo: IMS, 1983.

A arte no Brasil nas décadas de 1930-40: o Grupo Santa Helena. São Paulo: Nobel/EDUSP, 1991.

Walter Zanini: Vanguardas, desmaterialização, tecnologias na arte. Eduardo de Jesus (org.). São Paulo: Editora Martins Fontes, 2018. 


\title{
WALTER ZANINI AND THE MEDIATIONS OF CONTEMPORARY ART IN BRAZIL DURING REDEMOCRATIZATION
}

\begin{abstract}
Built on the study of institutional mediation processes and activities performed by cultural intermediaries, that tool a role in the consolidation of "contemporary art" as a new paradigm in Brazil's art history. I propose an analysis of this process, that took place throughout the 1970s and 1980s, articulating it to the restrictive and provocative conditions from the political experience of transition from a military-authoritarian regime to a democratic one. In this paper, I focus on the trajectory of a specific cultural intermediary, Walter Zanini, an art critic and historian, museologist, and professor, who was the director of the Contemporary Art Museum of the São Paulo University, between 1963 and 1978, and the first person in charge of the curatorial project for the São Paulo International Biennial, from 1980 to 1983, organizing its 16th and 17th editions.
\end{abstract}

Keywords: Sociology of art; Contemporary art; Exhibition curating; Sao Paulo Art Biennial.

\section{WALTER ZANINI Y LAS MEDIACIONES DEL ARTE CONTEMPORÁNEO EN EL BRASIL EN REDEMOCRATIZACIÓN}

Resumen: A partir del estudio de procesos de mediación institucional y actividades desarrolladas por agentes culturales intermediarios, que operaron en la emergencia y consolidación del "arte contemporáneo" como nuevo paradigma en la historia del arte de Brasil. Propongo un análisis de dicho proceso, que se dio al largo de los años 1970 y 1980, articulado a las condiciones limitantes y provocantes de una escena política que experimentaba transición gradual y tutelada de un régimen dictatorial-militar hacia la democracia. Enfoco el estudio sobre la trayectoria de un intermediario cultural específico, Walter Zanini, crítico e historiador de arte, museólogo y profesor, que dirigió el Museo de Arte Contemporáneo de la Universidad de San Pablo entre 1963 y 1978, y fue la primera persona a ocupar el cargo de curador general para la Bienal Internacional de San Pablo, entre 1980 y 1983, organizando sus $16^{a}$ y $17^{a}$ ediciones.

Palabras claves: Sociología del arte; Arte contemporáneo; Curaduría de exhibiciones; Bienal de San Pablo.

Tálisson Melo de Souza - Doutorando no Programa de Pós-graduação em Sociologia e Antropologia da Universidade Federal do Rio de Janeiro (bolsista do CNPq), com estágio de pesquisa no Center for Cultural Sociology da Yale University, Estados Unidos (bolsa PDSE/CAPES). Mestre pelo Programa de Pós-graduação em Artes, Cultura e Linguagens da Universidade Federal de Juiz de Fora, onde também se graduou bacharel em Artes e Design, com especialização em história da arte moderna e contemporânea na Universidad de Salamanca, Espanha. 